\title{
The Future of Low-emission Sustainable Cereal Intensification in SSA
}

Kindie Tesfaye ${ }^{1}$, Marloes van Loon², Hein ten Berge ${ }^{2}$, Renske Hijbeek ${ }^{2}$, Dawit Solomon ${ }^{3}$, Martin Van Ittersum ${ }^{2}$

December 13, 2021

1. International Maize and Wheat Improvement Centre (CIMMYT), Addis Ababa, Ethiopia

2. Wageningen University \& Research, P.O. Box 430, 6700AK Wageningen, The Netherlands

3. CGIAR Research Program on Climate Change, Agriculture and Food Security (CCAFS), East Africa Program, International Livestock Research Center, Addis Ababa, Ethiopia.

This document is part of a series of short papers on "The Future of X", produced as part of foresight-related research supported by the CGIAR Research Program on Policy, Institutions, and Markets, and edited by Keith Wiebe (IFPRI) and Steven Prager (Alliance of Bioversity and CIAT). These short papers are intended to provide a focused, forward-looking perspective on key issues to support discussion on food, land, and water systems transformation. We thank two anonymous reviewers for their comments on an earlier draft.

This is an accepted version presented as a pre-print. It is currently undergoing final revision, editing, and production. A final version will be made available at http://foresight.cgiar.org.

\section{What is the issue?}

Cereals account for approximately 50\% of caloric intake and total crop area in Sub Saharan Africa (SSA), playing a pivotal role in the food security of millions of people. Cereal demand in the region is projected to nearly triple by 2050 , mainly due to rapid population growth (2.3fold), and dietary changes [1]. To meet its cereal demand by 2050, SSA needs to attain $80 \%$ of the agronomic rainfed yield potential on its existing rainfed cereal cropland area, while today's yield level is only $20-40 \%$ [1]. Despite these large yield gaps (i.e. the gap between the farmers' yield and the agronomic rainfed yield potential), increases in cereal yields so far are very slow in most SSA countries and cropland expansion is substantial to keep up with the growing cereal demand [2]. However, area expansion is not a sustainable way of increasing cereal production in SSA due to limited availability of arable land, associated loss of forests and grasslands, increased loss of biodiversity, reduction in carbon stocks and substantial greenhouse gas (GHG) emissions, and the low profitability of low-input farming $[1,3]$. SSA has already seen a continuous increase in emissions from agriculture-driven deforestation between 1990 and 2015 [4]. Conventional intensification to meet increased demands would rely on increased use of fertilizers, which also come with a GHG footprint. Yet, expansion of cropland area will also result in major GHG emissions which stands against the Nationally Determined Contributions 
(NDC) of countries as per the Paris Agreement [5]. At the same time, cereal self-sufficiency for SSA is also of importance. While recognizing that self-sufficiency is not necessarily a precondition for food security, achieving at least a substantial degree of self-sufficiency is of great concern for low-income developing countries because many lack adequate foreign exchange reserves to pay for food imports and the required infrastructure to store and distribute it efficiently. Substantial reliance on food imports may also imply geo-political risks. Sustainable intensification, i.e., higher yields per unit area with efficient use of inputs, is considered as a major alternative pathway to increase productivity and to attain cereal selfsufficiency in SSA. This brief summarizes results of three recent studies that assessed whether SSA can be self-sufficient in cereals (maize, rice, wheat, sorghum, and millet) while minimizing GHG emission by 2050 under different scenarios of intensification on existing cereal area, as opposed to cropland area expansion.

\section{What research has been done?}

Three major studies were conducted on food self-sufficiency and intensification levels required to feed the increasing population in SSA by 2050 and associated GHG emissions. Specifically, the studies focused on: (i) analysis of cereal self-sufficiency in SSA by 2050 and estimation of the required level of yield increase to feed the increasing population [1], (ii) estimation of the minimum plant nutrient requirements to achieve the level of productivity required by 2050 , using maize as a case study [6], and (iii) estimation of GHG emission from different scenarios of increasing cereal production, ranging from intensifying production to agricultural area expansion [3]. In these studies, four yield increase scenarios were studied: cereal yields in 2050 are the same as the 2015 baseline year (S1); actual cereal yield trends over the period 19912014 are extrapolated to 2050 (S2); cereal yields in 2050 are $50 \%$ of water-limited (rainfed) potential yield (Yw) (S3); and cereal yields in 2050 are $80 \%$ of Yw (S4). In all scenarios, potential yield in 2050 was assumed to be the same as in 2015. Going from scenario S1 to S4, yields increase substantially and therefore crop area expansion decreases. Increased demands for crop nutrients ( $\mathrm{N}, \mathrm{P}$ and $\mathrm{K}$ ), and associated GHG emissions were quantified.

\section{What has the research found?}

The research results show that cereal self-sufficiency in SSA in 2050 is possible with current cereal area, but yields will have to increase to ca. $80 \%$ of $Y w$, which requires an unprecedented steep and continuous increase in production for rainfed systems (Figure 1). Nutrient limitation is amongst the main causes of yield gaps in SSA. Yet intensification of crop production in the region implies substantial increases in fertilizer input, which is strongly related to GHG emissions [6]. Analysis with maize show that the average minimum nitrogen $(\mathrm{N})$ requirements for attaining ca. $80 \%$ of rainfed yield potential will be ca. $140 \mathrm{~kg} \mathrm{~N} / \mathrm{ha}$ as compared to the current average fertilizer rate of ca. $10 \mathrm{~kg} \mathrm{~N} / \mathrm{ha}$ [6]. However, required $\mathrm{N}$ inputs vary with the level of agronomic nitrogen use efficiency (N-AE). If farmers manage nutrients properly and build soil fertility over years, such 'minimum requirements' will be sufficient in the long term; in 
other conditions nutrient requirements will be substantially higher, with subsequent impacts on GHG emissions [6].

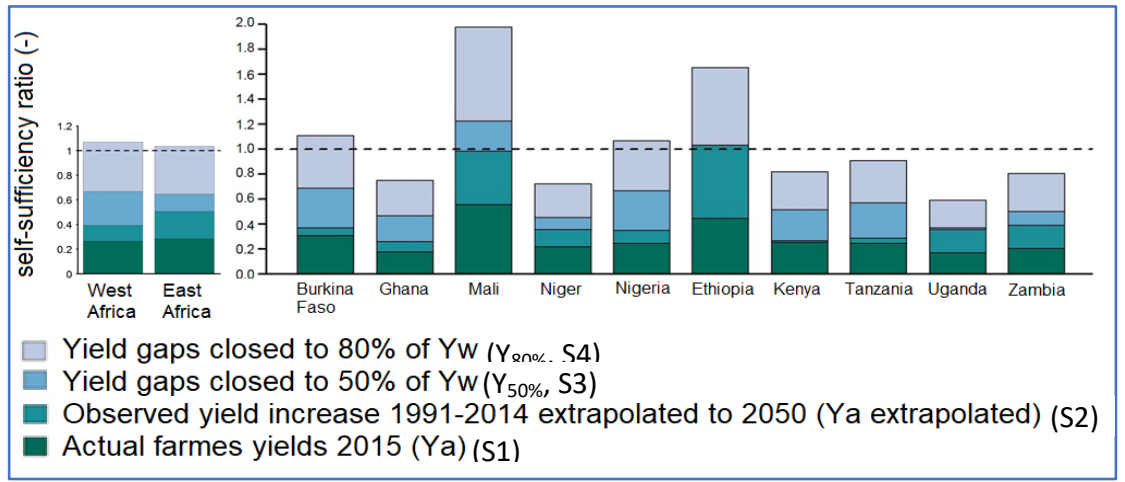

Figure 1. Self-sufficiency ratios attainable for the five main cereals (maize, millet, rice, sorghum and wheat) in 10 SSA countries by 2050 under four scenarios of yield increase on current cereal cropland area [1].

From the analysis of GHG emissions resulting from intensification and crop area expansion, it follows that intensification can bring lower GHG emissions than cropland expansion but gains in GHG depend on the level of agronomic nitrogen use efficiency (N-AE) achieved (Figure 2). Regardless of the scenarios considered, GHG emissions from cereal production such as maize will at least double by 2050 because of the steep increase in production needed to meet the demand. However, intensification to $80 \%$ of $Y w(S 4)$ under high agronomic nitrogen use efficiency led to ca. 4 times less GHG emissions than assuming no intensification (S1) and 3 times less than under the assumption of current yield trends extrapolated (S2).

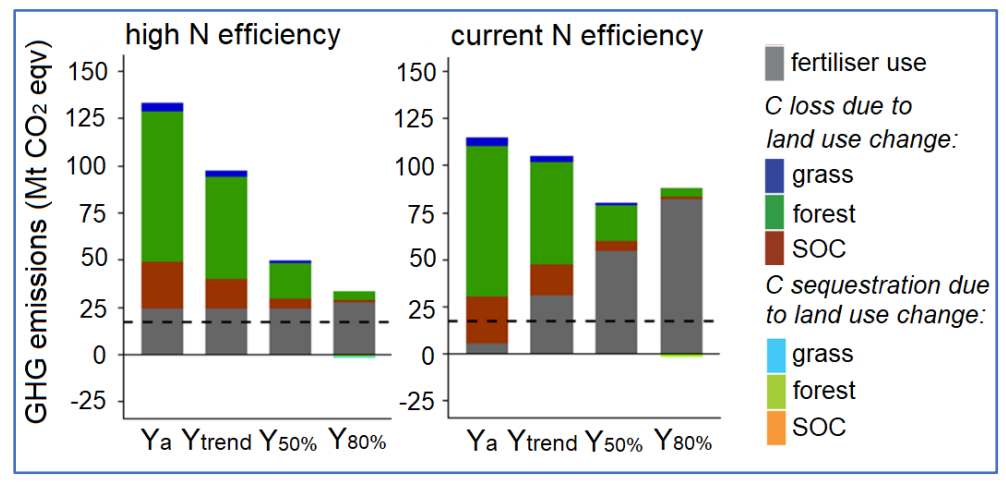

Figure 2. GHG emissions from maize production in SSA for four scenarios with increasing intensification and decreasing area expansion, and two levels of agronomic nitrogen use efficiency. The dashed line indicates GHG emissions in 2015, and $Y_{a}$ involves nutrient mining [3]. 
The results suggest that intensification of cereal production with sufficient and efficient use of fertilizers could lead to the lowest GHG emissions among the scenarios studied in future cereal productions in SSA. However, this requires excellent agronomy, including the use of welladapted cultivars, proper planting densities, good nutrient management and crop protection against weeds, pests, and diseases [3]. It should also be noted that intensification of cereal production may also have additional benefits, including improving the economic profitability for smallholders in SSA $[7,8]$.

\section{What gaps deserve further work?}

Future research needs to focus on nutrient management innovations and developing farmingsystem-based best-best agronomy packages, while accounting for the huge variation in climate, soil, and farming contexts. This must be complemented with socio-economic and policyoriented research to understand farmers' constraints, decision making and institutional environment. Further research is also needed on identifying options for making smallholder crop production more productive, climate smart and sustainable.

More information can be available at: $\underline{w w w . y i e l d g a p . o r g}$

\section{References}

1. van Ittersum, M. K. et al. Can sub-Saharan Africa feed itself? Proc. Natl. Acad. Sci. U. S. A. 113, 14964-14969 (2016).

2. Giller, K. E. The Future of Farming: Who will produce our food? Food Secuirity In Press, (2021).

3. van Loon, M. P. et al. Impacts of intensifying or expanding cereal cropping in sub-Saharan Africa on greenhouse gas emissions and food security. Glob. Chang. Biol. 25, 3720-3730 (2019).

4. Carter, S. et al. Agriculture-driven deforestation in the tropics from 1990-2015: Emissions, trends and uncertainties. Environ. Res. Lett. 13, (2018).

5. Erickson, L. E. \& Brase, G. Paris Agreement on Climate Change. in Reducing Greenhouse Gas Emissions and Improving Air Quality (eds. Erickson, L. E. \& Brase, G.) 11-22 (CRC Press Inc., 2020). doi:10.1201/9781351116589-2

6. ten Berge, H. F. M. et al. Maize crop nutrient input requirements for food security in subSaharan Africa. Glob. Food Sec. 23, 9-21 (2019).

7. Reich, J., Paul, S. S. \& Snapp, S. S. Highly variable performance of sustainable intensification on smallholder farms: A systematic review. Glob. Food Sec. 30, 100553 (2021).

8. Vanlauwe, B. et al. Sustainable intensification and the African smallholder farmer. Curr. Opin. Environ. Sustain. 8, 15-22 (2014). 